\title{
OVERHEAD POWER LINES MAGNETIC FIELD REDUCING IN MULTI-STORY BUILDING BY ACTIVE SHIELDING MEANS
}

\begin{abstract}
Aim. Reducing of magnetic flux density of magnetic field in multi-storey building, generated by overhead power lines to the sanitary standards level by active shielding means. The tasks of the work are the synthesis, Computer simulation and experimental research of three-circuits system of active shielding, which includes three shielding coils. Methodology. When synthesizing the system of active shielding of magnetic field, are determined their number, configuration, spatial arrangement and of shielding coils as well as the shielding coils currents and resulting magnetic flux density value in the shielding space. The synthesis is based on the multi-criteria game decision, in which the payoff vector is calculated on the basis on quasi-stationary approximation solutions of the Maxwell equations. The game decision is based on the stochastic particles multiswarm optimization algorithms. Results. Computer simulation and experimental research of three-circuit system of active shielding of magnetic field, generated by overhead power lines with phase conductors triangle arrangements in multi-storey building are given. The possibility of initial magnetic flux density level reducing in multi-storey building to the sanitary standards level is shown. Originality. For the first time to reducing of magnetic flux density of magnetic field in multi-storey building the synthesis, Computer simulation and experimental research of three-circuit system of active shielding of magnetic field generated by single-circuit overhead power line with phase conductors triangular arrangements carried out. Practical value. Practical recommendations from the point of view of the practical implementation on reasonable choice of the spatial arrangement of three shielding coils of three-circuit system of active shielding of the magnetic field generated by single-circuit overhead power line with phase conductors triangular arrangements in multi-storey building are given. References 41, figures 15.
\end{abstract}

Key words: overhead power lines with phase conductors triangle arrangements, magnetic field, system of active shielding, computer simulation, experimental research.

Цель. Снижение уровня индукиии магнитного поля внутри многоэтажного дома, генерируемого одноцепной воздушной линией электропередачи до уровня санитарных норм. Задачами работы являются синтез, компьютерное моделирование и экспериментальные исследования трехконтурной системы активного экранирования, содержащей три экранирующие обмотки. Методология. При синтезе системы определены - количество, конфигурация, пространственное расположение экранируюших обмоток, а также токи в экранирующих обмотках и результируюшие значения индукиии магнитного поля в пространстве экранирования. Синтез трехконтурной системы активного экранирования основан на решении многокритериальной стохастической игры, в которой векторный выигрыш вычисляется на основании решений уравнений Максвелла в квазистационарном приближении. Решение игры находится на основе алгоритмов стохастической мультиагентной оптимизации мультироем частии. Результаты. Приводятся результатьы компьютерного моделирования и экспериментальных исследований трехконтурной системы активного экранирования магнитного поля внутри многоэтажного дома, генерируемого воздушной линией электропередачи. Показана возможность снижения уровня индукиии исходного магнитного поля внутри многоэтажного дома до уровня санитарных норм. Оригинальность. Впервые для снижения уровня индукции магнитного поля внутри многоэтажного дома до уровня санитарных норм, проведены синтез, компьютерное моделирование и экспериментальные исследования трехконтурной системь активного экранирования магнитного поля, генерируемого одноцепной воздушной линией электропередачи с треугольным подвесом проводов. Практическая ценность. Приводятся практические рекомендации по обоснованному выбору, с точки зрения практической реализачии, пространственного расположения трех экранирующих обмоток трехконтурной системы активного экранирования магнитного поля, от генерируемого внутри многоэтажного дома магнитного поля одноконтурной воздушной линии электропередачи с треугольным подвесом проводов. Библ. 41, рис. 15.

Key words: воздушные линии электропередачи с треугольным расположением фазных проводов, магнитное поле, система активного экранирования, компьютерное моделирование, экспериментальное исследование.

Introduction. Overhead power lines often run near residential buildings. These lines generate a power frequency magnetic field (MF) in residential buildings, the level of which often exceeds sanitary standards $[1,2]$. To normalize the level of the magnetic field, it is most effective and economically feasible to use active screening methods [3, 4]. In an active shielding system (SAS), a compensating magnetic field is generated using shielding coils [5-18].

The number, spatial arrangement of shielding windings and their ampere turns are determined by the type of power transmission line and currents in the conductors of power transmission lines, as well as the spatial location of the shielding zone and its size, as well as the level of induction, which must be provided by means of active shielding. The simplest system is the single-circuit system, which contains only one - single shielding coil. With the help of such a system, it is possible to effectively screen a weakly polarized magnetic field, in which the space-time characteristic has the form of a highly elongated ellipse, which approaches a straight line.

However, the greatest difficulty for active shielding is a highly polarized magnetic field. The shape of the space-time characteristic of such a magnetic field approaches a circle. In particular, such a magnetic field is generated by a single-circuit power line with a triangleshaped arrangement of wires. Active shielding of such a magnetic field requires at least two shielding coils.

In Ukraine, in the zones of old buildings, there are mainly five-storey residential buildings. In this case,

(c) B.I. Kuznetsov, T.B. Nikitina, I.V. Bovdui, V.V. Kolomiets, B.B. Kobylianskiy 
single-circuit $110 \mathrm{kV}$ power lines with wires in the shape of a triangle pass most often near these residential buildings.

Most of the research focuses on reducing the magnetic field in one-story houses or even in a separate room at home [5-19]. Therefore, an urgent task is to reduce the magnetic field in the entire multi-storey building.

The aim of the work is reduce the level of magnetic flux density of the magnetic field in multi-storey building generated by single-circuit overhead power line by active shielding means. The tasks of the work are the synthesis, Computer simulation and experimental research of threecircuits system of active shielding.

Statement of the research problem. Let us consider the synthesis of system of active shielding of a magnetic field in a multi-story building. The magnetic field in a multi-story building is generated by a singlecircuit overhead power transmission line with a spatial arrangement of wires in the shape of a triangle. In Fig. 1 are shown the layout of an overhead transmission line, a multi-story building, in which it is necessary to reduce the level of the initial magnetic field to sanitary standards of Ukraine.

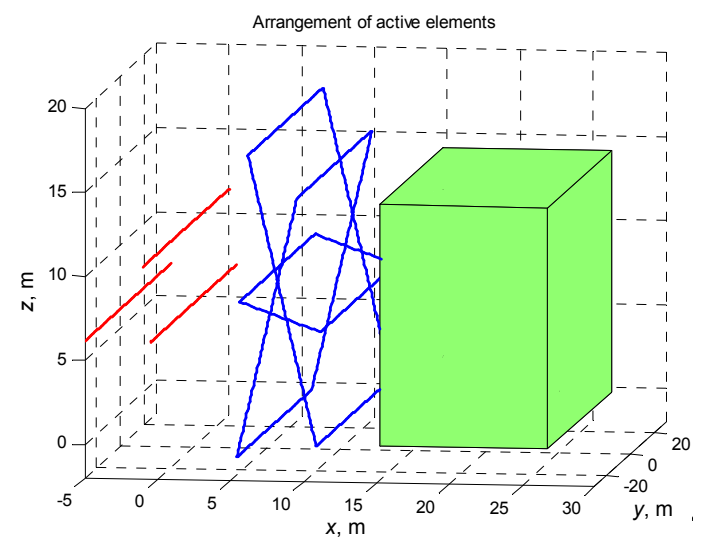

Fig. 1. The location of $110 \mathrm{kV}$ overhead power line, three shielding coils and shielding space in multi-story building

Let us introducing the vector of unknown parameters the components of which are the number and coordinates of shielding coils as well as parameters of the regulator [19-23] and vector of uncertainty parameters [24-28]. Then the calculate of vector of unknown parameters of system of active shielding and of vector of uncertainty parameters in the form of a solution of multi-criteria game. The components vector payoff in this game is levels of magnetic flux density at points of the shielding space. These components are nonlinear functions of the vectors of unknown parameters and uncertainty parameters and are calculated on basis of Maxwell equations quasi-stationary approximation solutions [3]. First player is vector of unknown parameters and its strategy is minimization of vector payoff. Second player is vector of uncertainty parameters and this strategy is maximization of the same vector payoff [29].

Therefore, the solution of multi-criteria game is calculated from the condition of minimum value of vector payoff for the vector of unknown parameters but the maximum value of vector payoff for the vector uncertainty parameters. This technique corresponds to the standard worst-case robust systems synthesis approach [27, 28].

To find multi-criterion game solution from Paretooptimal set solutions taking into account binary preference relations [29-32] used particle multiswarm optimization algorithm [33-41], in which swarms number equal number of vector payoff components.

Computer simulation results. Consider the result of synthesis of SAS of MF with circular space-time characteristic created by three-phase single-circuit overhead power line $110 \mathrm{kV}$ with phase conductors triangular arrangements in a multi-story building, as it is shown in Fig. 1. In order to reduce the level of magnetic flux density of the initial magnetic field throughout the entire multi-story building to the level of sanitary standards of Ukraine, in this case, it is necessary to use three shielding windings, as it is shown in Fig. 1.

In Fig. 2 are shown lines of equal level of module of the resultant magnetic flux density with the system of active shielding is on. As follows from this figure, the level of magnetic flux density of the resulting magnetic field in the entire space of a multi-storey building does not exceed the level of $0.5 \mu \mathrm{T}$, which corresponds to the sanitary standards of Ukraine. Note that in the center of the multi-storey building under consideration, the level of magnetic flux density of the resulting magnetic field does not exceed $0.2 \mu \mathrm{T}$. Therefore, in this part of the space, using an system of active shielding, the induction level of magnetic flux density of the initial magnetic field can be reduced by more than 20 times.

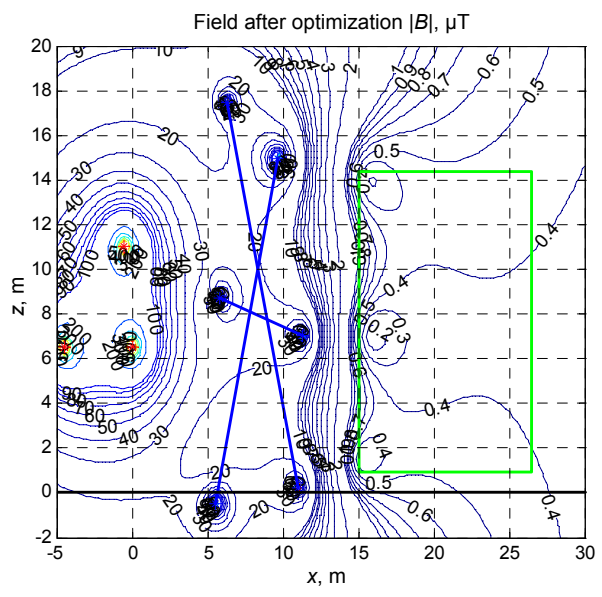

Fig. 2. Isolines of the resultant magnetic flux density with the system of active shielding is on

In Fig. 3 are shown the space-time characteristics of the magnetic flux density vector of magnetic field generated by: 1) overhead power line; 2) all three shielding coils and 3) the resultant magnetic field with the system of active shielding.

In Fig. 4 are shown the dependences of the of levels of the magnetic flux density of the initial magnetic field and the resultant magnetic field when the system of active shielding is on as a function of the distance from the extreme conductor of the power line. As can be seen from this figure, the system of active shielding is reduced the level of the magnetic flux density of the initial magnetic field by more 10 times from $4.25 \mu \mathrm{T}$ to $0.4 \mu \mathrm{T}$ and therefore the shielding factor is more 10 . 


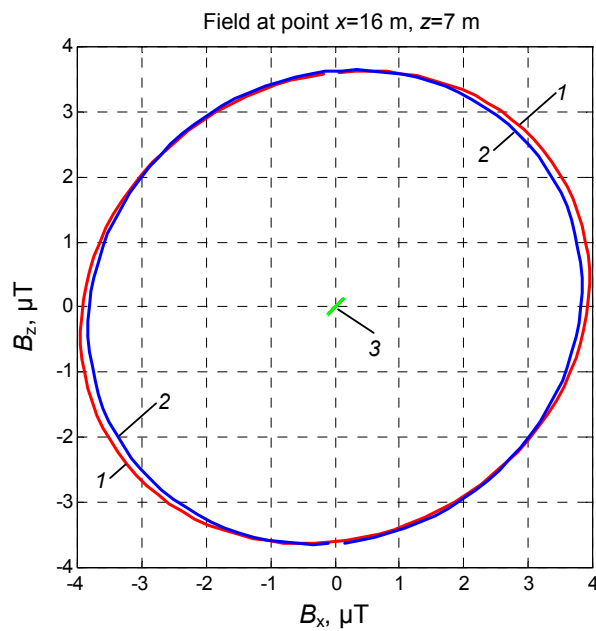

Fig. 3. Comparison between space-time characteristics of magnetic flux density without and with system of active shielding with all three shielding coils and only all three shielding coils

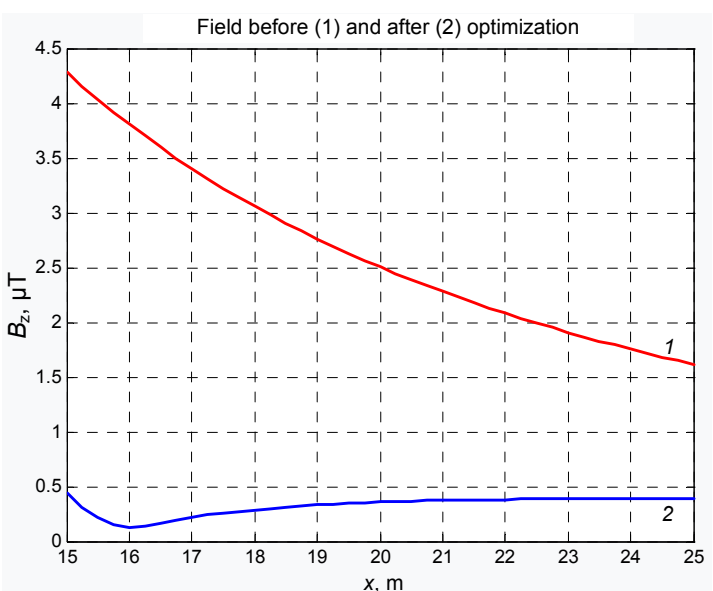

Fig. 4. Comparison of magnetic flux density level between with and without system of active shielding

Now let us consider the shielding efficiency of the original magnetic field when only one single firs shielding coil is used at optimal values of the regulator of this coil.

In Fig. 5 are shown the space-time characteristics of the magnetic flux density vector of magnetic field generated by: 1) overhead power line; 2) only one single firs shielding coils and 3 ) the resultant magnetic field with the only one single firs shielding coils.

In Fig. 6 are shown the dependences of the of levels of the magnetic flux density of the initial magnetic field and the resultant magnetic field when the only single first shielding coil of system of active shielding is on as a function of the distance from the extreme conductor of the power line.

As can be seen from this figure, with only one single first shielding coil of the active shielding system, the level of magnetic flux density of the initial magnetic field is increased in 1.19 times in the considered space from $4.25 \mu \mathrm{T}$ to the level of $5 \mu \mathrm{T}$ due to overcompensation.

Now let us consider the shielding efficiency of the original magnetic field when only one single second shielding coil is used at optimal values of the regulator of this coil. In Fig. 7 are shown the space-time characteristics of the magnetic flux density vector of magnetic field generated by: 1) overhead power line; 2) only one single second shielding coils and 3) the resultant magnetic field with the only one single second shielding coils.

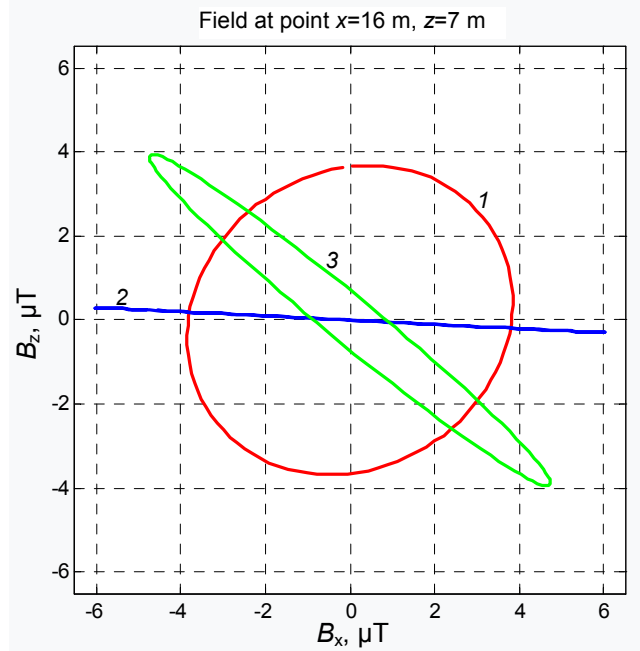

Fig. 5. Comparison between space-time characteristics of magnetic flux density without and with system of active shielding with only single first shielding coil

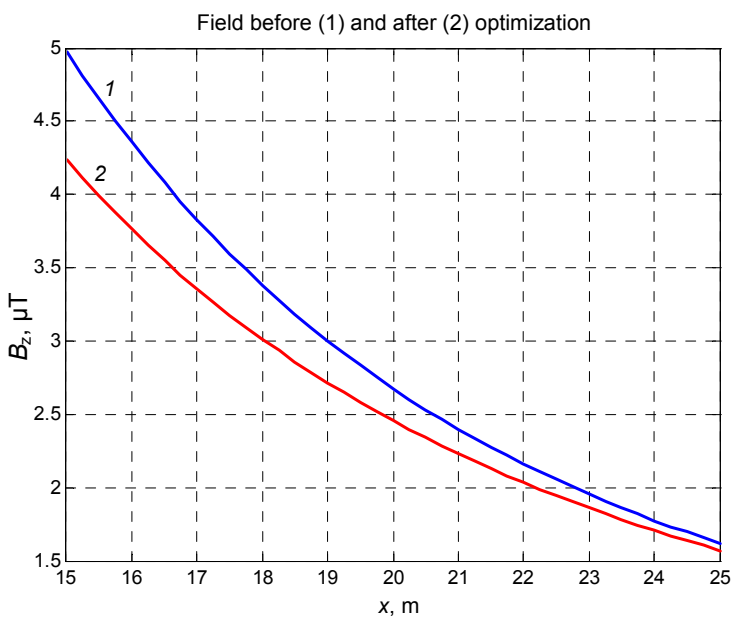

Fig. 6. Comparison of magnetic flux density between with and without system of active shielding with only single first shielding coil

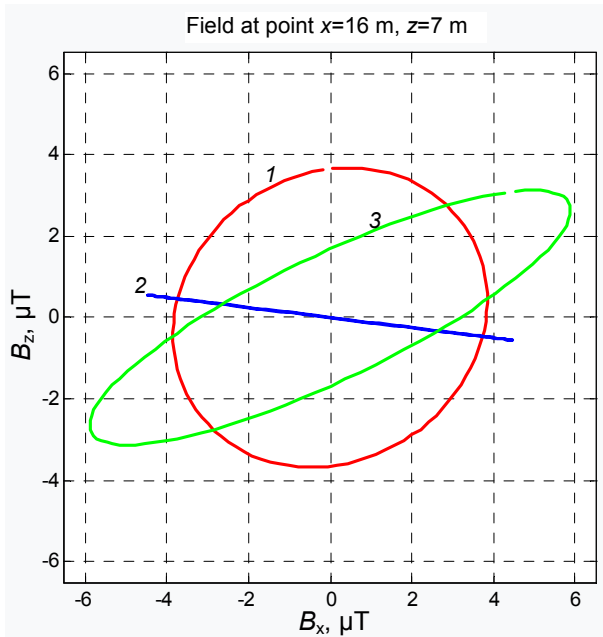

Fig. 7. Comparison between space-time characteristics of magnetic flux density without and with system of active shielding with only single second shielding coil and only single second shielding coil 
In Fig. 8 are shown the dependences of the of levels of the magnetic flux density of the initial magnetic field and the resultant magnetic field when the only single second shielding coil of system of active shielding is on as a function of the distance from the extreme conductor of the power line. As can be seen from this figure, with only one single second shielding coil of the active shielding system, the level of magnetic flux density of the initial magnetic field is increased in 1.28 times in the considered space from $4.25 \mu \mathrm{T}$ to the level of $5.4 \mu \mathrm{T}$ due to overcompensation.

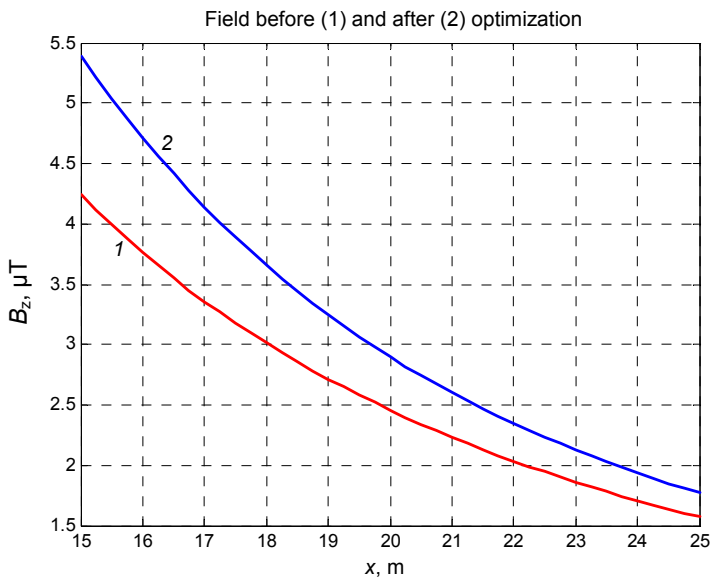

Fig. 8. Comparison of magnetic flux density between with and without system of active shielding with only single second shielding coil

Now let us consider the shielding efficiency of the original magnetic field when only one single third shielding coil is used at optimal values of the regulator of this coil. In Fig. 9 are shown the space-time characteristics of the magnetic flux density vector of magnetic field generated by: 1) overhead power line; 2) only one single third shielding coils and 3) the resultant magnetic field with the only one single third shielding coils.

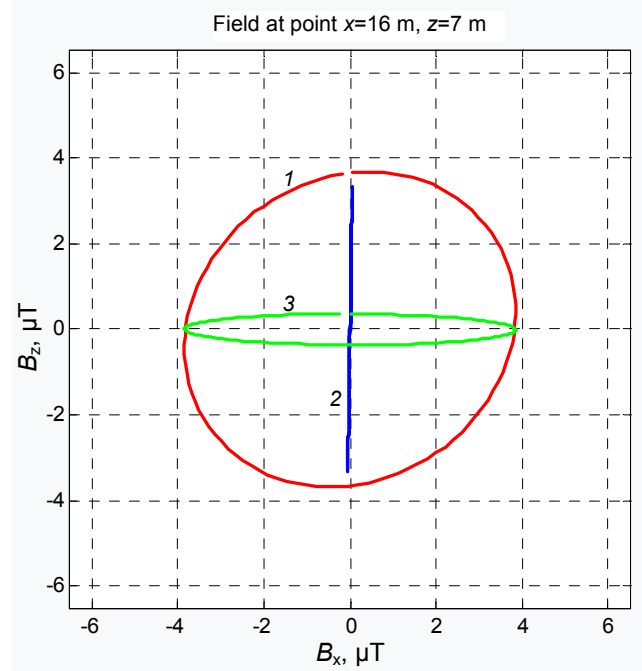

Fig. 9. Comparison between space-time characteristics of magnetic flux density without and with system of active shielding with only single third shielding coil and only single third shielding coil

In Fig. 10 are shown the dependences of the of levels of the magnetic flux density of the initial magnetic field and the resultant magnetic field when the only single third shielding coil of system of active shielding is on as a function of the distance from the extreme conductor of the power line.

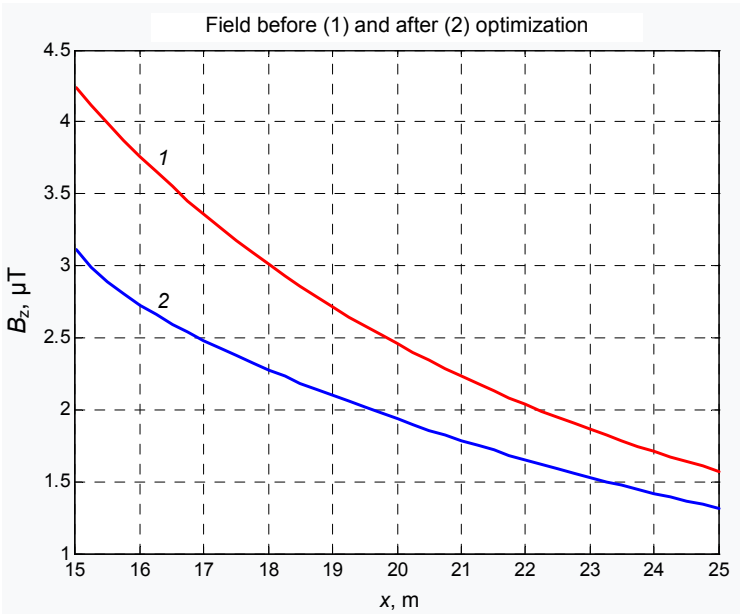

Fig. 10. Comparison of magnetic flux density between with and without system of active shielding with only single third shielding coil

As can be seen from this figure, with only one third of the winding of the active shielding system, the level of the magnetic flux density of the initial magnetic field is reduced in 1.35 times in the considered space from $4.25 \mu \mathrm{T}$ to the level of $3.25 \mu \mathrm{T}$.

Now let us consider the shielding efficiency of the original magnetic field when only both first and second shielding coils are used at optimal values of the regulator of these coils. In Fig. 11 are shown the space-time characteristics of the magnetic flux density vector of magnetic field generated by: 1) overhead power line; 2) only both first and second shielding coils and 3) the resultant magnetic field with the only both first and second shielding coils.

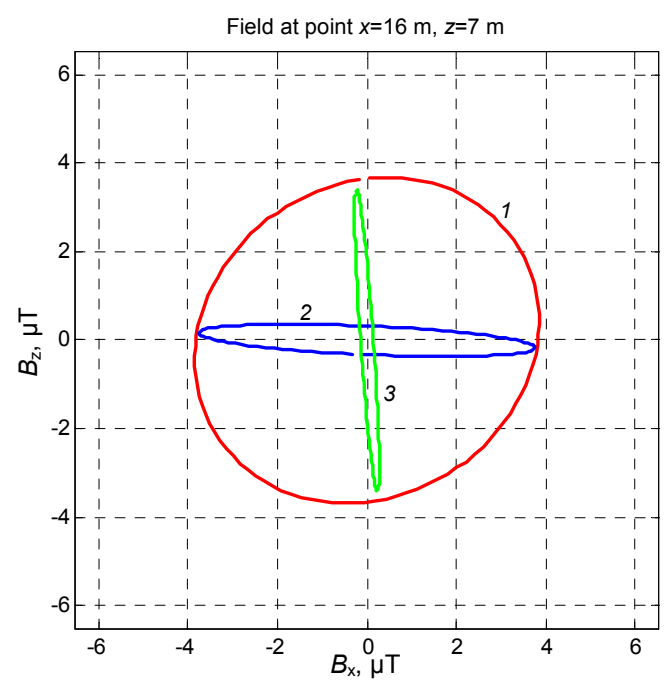

Fig. 11. Comparison between space-time characteristics of magnetic flux density without and with system of active shielding with only both first and second shielding coils and only both first and second shielding coils

In Fig. 12 are shown the dependences of the of levels of the magnetic flux density of the initial magnetic field and the resultant magnetic field when the only both 
first and second shielding coils of system of active shielding are on as a function of the distance from the extreme conductor of the power line.

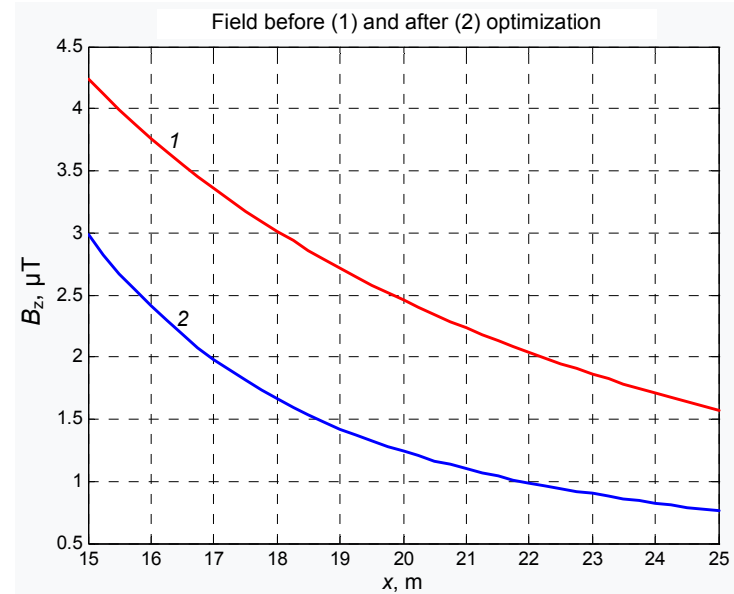

Fig. 12. Comparison of magnetic flux density between with and without system of active shielding with only both first and second shielding coils

As can be seen from this figure, with only both first and second shielding coils of the active shielding system, the level of magnetic flux density of the initial magnetic field is reduced in 1.35 times in the considered space from $4.25 \mu \mathrm{T}$ to the level of $3.25 \mu \mathrm{T}$.

Experimental research. For experimental research, a laboratory model of a three-coil system of active shielding of a magnetic field generated by an air power line in a multi-storey building has been developed.

In Fig. 13 is shown a general view of the layout of the synthesized laboratory model of a three-coil system of active shielding.

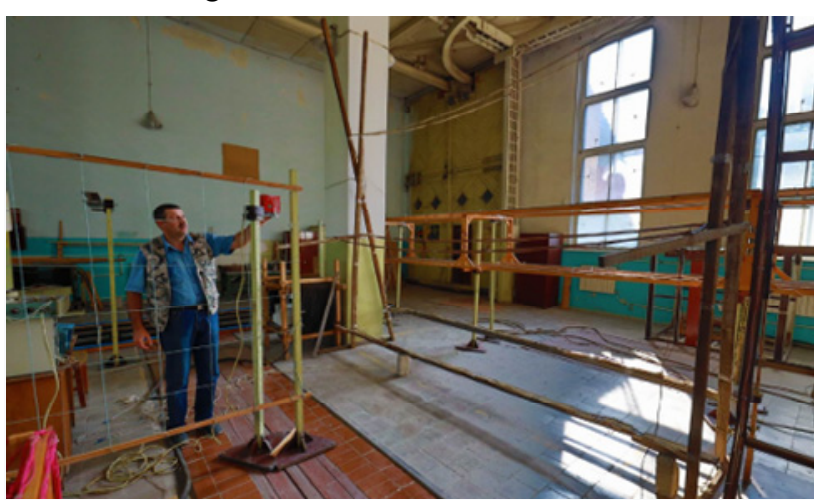

Fig. 13. Picture of three shielding coils spatial arrangement of system of active shielding laboratory model

To adjust the model of the system of active shielding, the space-time characteristic of the magnetic field was experimentally measured using two measuring windings and oscilloscope [31, 32].

As an example, in Fig. 14 are shown oscillograms of the output signals of the sensors $(a)$ and experimentally measured space-time characteristics $(b)$ of the output magnetic field.

In Fig. 15 are shown comparison of magnetic flux density between measurements (solid lines) and simulations (indicated by $\boldsymbol{+}$ ) with and without system of active shielding.

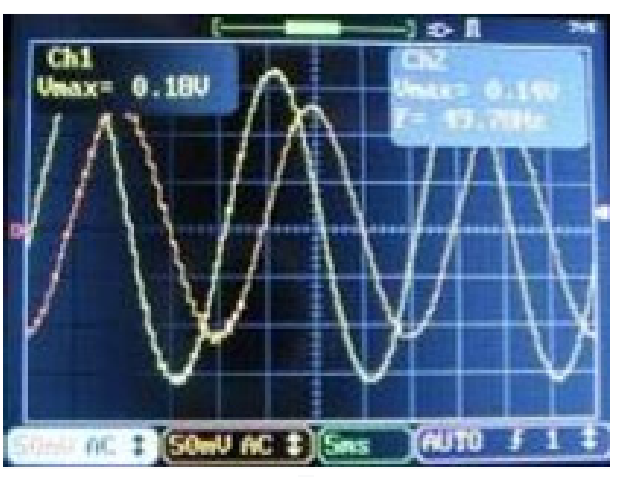

$a$

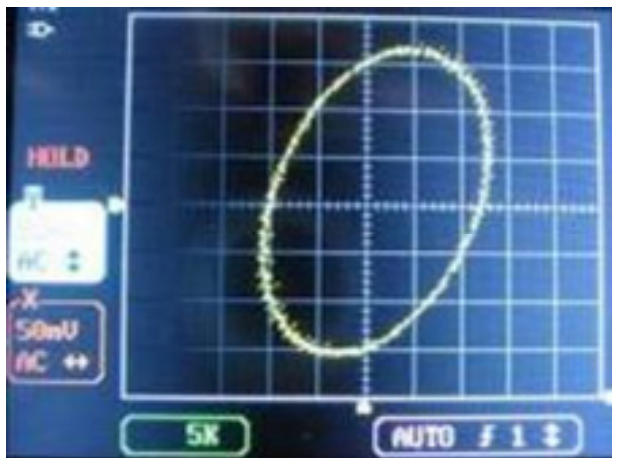

$b$

Fig. 14. Oscillograms of the output signals of the both sensors (a) and experimentally measured space-time characteristics $(b)$ of the magnetic field

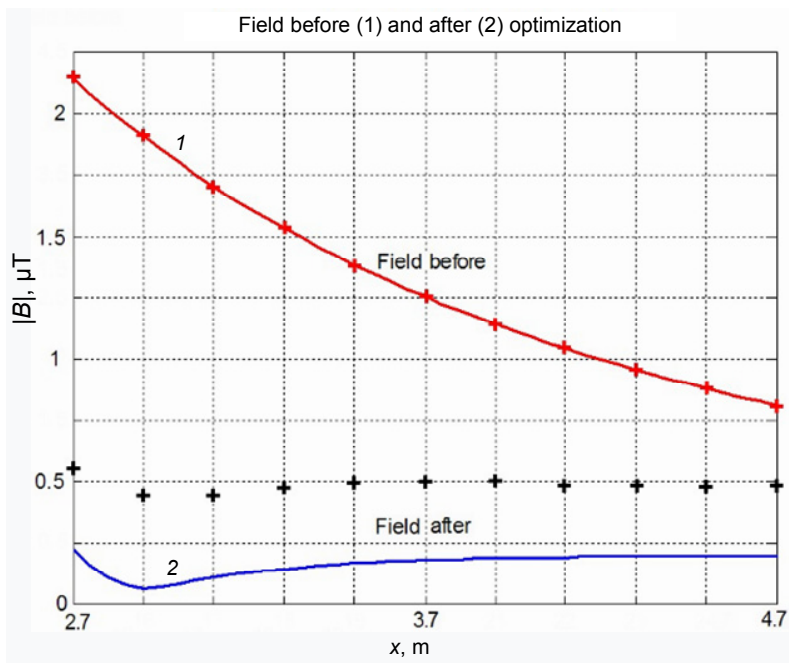

Fig. 15. Comparison of magnetic flux density between measurements (solid lines) and simulations (+) with and without system of active shielding

Note that from a comparison of the spatio-temporal characteristics shown in Fig. 9 and Fig. 11 follows that the space-time characteristic of the resulting magnetic field remaining after the operation of the only first and second shielding coil is a highly elongated ellipse. The major axis elongated ellipse spatio-temporal characteristics practically coincides with the space-time characteristics of the magnetic field generated by only one third shielding coil.

As a result, with the help of the third shielding coil, the major axis of the space-time characteristic of the resulting magnetic field, which remains after the operation of the only first and second shielding coils, is compensated effectively. Due to such compensation, 
a sufficiently high shielding factor of 10.75 is provided in the system with the simultaneous operation of all three shielding coils.

As can be seen from Fig. 15 the experimental value of the induction level does not exceed $0.5 \mu \mathrm{T}$. The deviation of the experimental value of the induction level from the calculated one is due, firstly, to the deviation of the geometric dimensions of the shielding windings from their calculated values, and, secondly, to the inaccuracy of adjusting the parameters of the regulators.

\section{Conclusions.}

1. For the first time, to reduce the initial magnetic field in multi-storey building generated by a high-voltage power line by active shielding means, the three-circuits system of active shielding which contains three shielding coils was designed.

2. As a result of computer simulation of the synthesized system, it is shown that with the help of the synthesized system, the level of magnetic flux density of the magnetic field in a multi-storey building generated by a high-voltage power line is reduced by more than 10 times. At the same time, the level of magnetic flux density of the resulting magnetic field in multi-storey building does not exceed the sanitary standards of Ukraine.

3 . To set up a laboratory model of a three-circuit system of active shielding, a computer simulation of the effectiveness of shielding the initial magnetic field in a multi-storey building using separate windings was carried out. It is shown, that when only one coil is in operation, the level of the magnetic flux density increases by a factor of 1.2-1.5 due to overcompensation. When only two windings work, it is not possible to ensure the sanitary standards of Ukraine in terms of the magnetic flux density level in the multi-storey building.

4. As the results of experimental studies of a laboratory model of a three-circuit system of active shielding of a magnetic field in a multi-storey building generated by a high-voltage power line are presented, it has been established that the shielding factor is more than 4 units. The deviation of the experimental value of the level of magnetic flux density from the calculated one is due, firstly, to the deviation of the geometric dimensions of the shielding windings from their calculated values, and, secondly, to the inaccuracy of adjusting the parameters of the regulators.

\section{REFERENCES}

1. Rozov V.Yu., Grinchenko V.S., Yerisov A.V., Dobrodeyev P.N. Efficient shielding of three-phase cable line magnetic field by passive loop under limited thermal effect on power cables. Electrical Engineering \& Electromechanics, 2019, no. 6, pp. 5054. doi: https://doi.org/10.20998/2074-272x.2019.6.07.

2. Rozov V., Grinchenko V. Simulation and analysis of power frequency electromagnetic field in buildings closed to overhead lines. 2017 IEEE First Ukraine Conference on Electrical and Computer Engineering (UKRCON), Kyiv, UKraine, 2017, pp. 500-503. doi: https://doi.org/10.1109/ukrcon.2017.8100538.

3. Rozov V.Yu., Kundius K.D., Pelevin D.Ye. Active shielding of external magnetic field of built-in transformer substations. Electrical Engineering \& Electromechanics, 2020, no. 3, pp. 2430. doi: https://doi.org/10.20998/2074-272x.2020.3.04.

4. Rozov V.Y., Zavalnyi A.V., Zolotov S.M., Gretskikh S.V. The normalization methods of the static geomagnetic field inside houses. Electrical Engineering \& Electromechanics,
2015, no. 2, pp. 35-40. doi: https://doi.org/10.20998/2074272x.2015.2.07.

5. Salceanu A., Paulet M., Alistar B.D., Asiminicesei O. Upon the contribution of image currents on the magnetic fields generated by overhead power lines. 2019 International Conference on Electromechanical and Energy Systems (SIELMEN). 2019. doi: https://doi.org/10.1109/sielmen.2019.8905880.

6. Del Pino Lopez J.C., Romero P.C. Influence of different types of magnetic shields on the thermal behavior and ampacity of underground power cables. IEEE Transactions on Power Delivery, Oct. 2011, vol. 26, no. 4, pp. 2659-2667. doi: https://doi.org/10.1109/tpwrd.2011.2158593.

7. Ippolito L., Siano P. Using multi-objective optimal power flow for reducing magnetic fields from power lines. Electric Power Systems Research, Feb. 2004, vol. 68, no. 2, pp. 93-101. doi: https://doi.org/10.1016/s0378-7796(03)00151-2.

8. Barsali S., Giglioli R., Poli D. Active shielding of overhead line magnetic field: Design and applications. Electric Power Systems Research, May 2014, vol. 110, pp. 55-63. doi: https://doi.org/10.1016/j.epsr.2014.01.005.

9. Bavastro D., Canova A., Freschi F., Giaccone L., Manca M. Magnetic field mitigation at power frequency: design principles and case studies. IEEE Transactions on Industry Applications, May 2015, vol. 51, no. 3, pp. 2009-2016. doi: https://doi.org/10.1109/tia.2014.2369813.

10. Beltran H., Fuster V., García M. Magnetic field reduction screening system for a magnetic field source used in industrial applications. 9 Congreso Hispano Luso de Ingeniería Eléctrica (9 CHLIE), Marbella (Málaga, Spain), 2005, pp. 84-99. Available

https://www.researchgate.net/publication/229020921 Magnetic field reduction screening system for a magnetic field sour ce used in industrial applications (Accessed 28.10.2020).

11. Bravo-Rodríguez J., Del-Pino-López J., Cruz-Romero P. A Survey on Optimization Techniques Applied to Magnetic Field Mitigation in Power Systems. Energies, 2019, vol. 12, no. 7, p. 1332. doi: https://doi.org/10.3390/en12071332.

12. Canova A., del-Pino-López J.C., Giaccone L., Manca M. Active Shielding System for ELF Magnetic Fields. IEEE Transactions on Magnetics, March 2015, vol. 51, no. 3, pp. 1-4. doi: https://doi.org/10.1109/tmag.2014.2354515.

13. Canova A., Giaccone L. Real-time optimization of active loops for the magnetic field minimization. International Journal of Applied Electromagnetics and Mechanics, Feb. 2018, vol. 56, pp. 97-106. doi: https://doi.org/10.3233/jae-172286.

14. Canova A., Giaccone L., Cirimele V. Active and passive shield for aerial power lines. Proc. of the 25th International Conference on Electricity Distribution (CIRED 2019), 3-6 June 2019, Madrid, Spain. Paper no. 1096. Available at: https://www.cired-repository.org/handle/20.500.12455/290

(Accessed 28.10.2020).

15. Canova A., Giaccone L. High-performance magnetic shielding solution for extremely low frequency (ELF) sources. CIRED - Open Access Proceedings Journal, Oct. 2017, vol. 2017, no. 1, pp. 686-690. doi: https://doi.org/10.1049/oapcired.2017.1029.

16. Celozzi S. Active compensation and partial shields for the power-frequency magnetic field reduction. 2002 IEEE International Symposium on Electromagnetic Compatibility, Minneapolis, MN, USA, 2002, vol. 1, pp. 222-226. doi: https://doi.org/10.1109/isemc.2002.1032478.

17. Celozzi S., Garzia F. Active shielding for power-frequency magnetic field reduction using genetic algorithms optimization. IEE Proceedings - Science, Measurement and Technology, 2004, vol. 151, no. 1, pp. 2-7. doi: https://doi.org/10.1049/ipsmt:20040002.

18. Celozzi S., Garzia F. Magnetic field reduction by means of active shielding techniques. WIT Transactions on Biomedicine 
and Health, 2003, vol. 7, pp. 79-89. doi: https://doi.org/10.2495/ehr030091.

19. Buriakovskyi S.G., Maslii A.S., Pasko O.V., Smirnov V.V. Mathematical modelling of transients in the electric drive of the switch - the main executive element of railway automation. Electrical Engineering \& Electromechanics, 2020, no. 4, pp. 1723. doi: https://doi.org/10.20998/2074-272X.2020.4.03.

20. Ostroverkhov M., Chumack V., Monakhov E., Ponomarev A. Hybrid Excited Synchronous Generator for Microhydropower Unit. 2019 IEEE 6th International Conference on Energy Smart Systems (ESS), Kyiv, Ukraine, 2019, pp. 219-222. doi: https://doi.org/10.1109/ess.2019.8764202.

21. Ostroverkhov M., Chumack V., Monakhov E. Ouput Voltage Stabilization Process Simulation in Generator with Hybrid Excitation at Variable Drive Speed. 2019 IEEE 2nd Ukraine Conference on Electrical and Computer Engineering (UKRCON), Lviv, Ukraine, 2019, pp. 310-313. doi: https://doi.org/10.1109/ukrcon.2019.8879781.

22. Tytiuk V., Chornyi O., Baranovskaya M., Serhiienko S., Zachepa I., Tsvirkun L., Kuznetsov V., Tryputen N. Synthesis of a fractional-order $\mathrm{PI}^{\lambda} \mathrm{D}^{\mu}$-controller for a closed system of switched reluctance motor control. Eastern-European Journal of Enterprise Technologies, 2019, no. 2 (98), pp. 35-42. doi: https://doi.org/10.15587/1729-4061.2019.160946.

23. Zagirnyak M., Chornyi O., Zachepa I. The autonomous sources of energy supply for the liquidation of technogenic accidents. Przeglad Elektrotechniczny, 2019, no. 5, pp. 47-50. doi: https://doi.org/10.15199/48.2019.05.12.

24. Chornyi O., Serhiienko S. A virtual complex with the parametric adjustment to electromechanical system parameters. Technical Electrodynamics, 2019, pp. 38-41. doi: https://doi.org/10.15407/techned2019.01.038.

25. Shchur I., Kasha L., Bukavyn M. Efficiency Evaluation of Single and Modular Cascade Machines Operation in Electric Vehicle. 2020 IEEE 15th International Conference on Advanced Trends in Radioelectronics, Telecommunications and Computer Engineering (TCSET), Lviv-Slavske, Ukraine, 2020, pp. 156161. doi: https://doi.org/10.1109/tcset49122.2020.235413.

26. Shchur I., Turkovskyi V. Comparative Study of Brushless DC Motor Drives with Different Configurations of Modular Multilevel Cascaded Converters. 2020 IEEE 15th International Conference on Advanced Trends in Radioelectronics, Telecommunications and Computer Engineering (TCSET), Lviv-Slavske, Ukraine, 2020, pp. 447-451. doi: https://doi.org/10.1109/tcset49122.2020.235473.

27. Sushchenko O.A., Shyrokyi O.V. H2/Hळo optimization of system for stabilization and control by line-of-sight orientation of devices operated at UAV. 2015 IEEE International Conference Actual Problems of Unmanned Aerial Vehicles Developments (APUAVD), Kyiv, UKraine, 2015, pp. 235-238. doi: https://doi.org/10.1109/apuavd.2015.7346608.

28. Sushchenko O.A., Golitsyn V.O. Data processing system for altitude navigation sensor. 2016 th International Conference on Methods and Systems of Navigation and Motion Control (MSNMC), Kiev, Ukraine, 2016, pp. 84-87. doi: https://doi.org/10.1109/msnmc.2016.7783112.

29. Gal'chenko, V.Y., Vorob'ev, M.A. Structural synthesis of attachable eddy-current probes with a given distribution of the probing field in the test zone. Russian Journal of Nondestructive Testing, Jan. 2005, vol. 41, no. 1, pp. 29-33. doi: https://doi.org/10.1007/s11181-005-0124-7.

30. Halchenko, V.Y., Ostapushchenko, D.L. \& Vorobyov, M.A. Mathematical simulation of magnetization processes of arbitrarily shaped ferromagnetic test objects in fields of given spatial configurations. Russian Journal of Nondestructive Testing, Sep. 2008, vol. 44, no. 9, pp. 589-600. doi: https://doi.org/10.1134/S1061830908090015.
31. Chystiakov P., Chornyi O., Zhautikov B., Sivyakova G. Remote control of electromechanical systems based on computer simulators. 2017 International Conference on Modern Electrical and Energy Systems (MEES), Kremenchuk, Ukraine, 2017, pp. 364-367. doi: https://doi.org/10.1109/mees.2017.8248934.

32. Zagirnyak M., Bisikalo O., Chorna O., Chornyi O. A Model of the Assessment of an Induction Motor Condition and Operation Life, Based on the Measurement of the External Magnetic Field. 2018 IEEE 3rd International Conference on Intelligent Energy and Power Systems (IEPS), Kharkiv, 2018, pp. 316-321. doi: https://doi.org/10.1109/ieps.2018.8559564.

33. Ummels M. Stochastic Multiplayer Games Theory and Algorithms. Amsterdam University Press, 2010. 174 p.

34. Shoham Y., Leyton-Brown K. Multiagent Systems: Algorithmic, Game-Theoretic, and Logical Foundations. Cambridge University Press, 2009. 504 p.

35. Ray T., Liew K.M. A Swarm Metaphor for Multiobjective Design Optimization. Engineering Optimization, 2002, vol. 34, no. 2, pp. 141-153. doi: https://doi.org/10.1080/03052150210915. 36. Zilzter Eckart. Evolutionary algorithms for multiobjective optimizations: methods and applications. PhD Thesis Swiss Federal Institute of Technology, Zurich, 1999. 114 p.

37. Xiaohui Hu, Eberhart R.C., Yuhui Shi. Particle swarm with extended memory for multiobjective optimization. Proceedings of the 2003 IEEE Swarm Intelligence Symposium. SIS'03 (Cat. No.03EX706), Indianapolis, IN, USA, 2003, pp. 193-197. doi: https://doi.org/10.1109/sis.2003.1202267.

38. Pulido G.T., Coello C.A.C. A constraint-handling mechanism for particle swarm optimization. Proceedings of the 2004 Congress on Evolutionary Computation (IEEE Cat. No.04TH8753), Portland, OR, USA, 2004, vol. 2, pp. 13961403. doi: https://doi.org/10.1109/cec.2004.1331060.

39. Michalewicz Z., Schoenauer M. Evolutionary Algorithms for Constrained Parameter Optimization Problems. Evolutionary Computation, 1996, vol. 4, no. 1, pp. 1-32. doi: https://doi.org/10.1162/evco.1996.4.1.1.

40. Parsopoulos K.E., Vrahatis M.N. Particle swarm optimization method for constrained optimization problems. Proceedings of the Euro-International Symposium on Computational Intelligence, 2002, pp. 174-181.

41. Xin-She Yang, Zhihua Cui, Renbin Xiao, Amir Hossein Gandomi, Mehmet Karamanoglu. Swarm Intelligence and BioInspired Computation: Theory and Applications, Elsevier Inc., 2013. $450 \mathrm{p}$.

Received 28.12.2020 Accepted 05.02.2020

Published 05.04.2021

B.I. Kuznetsov ${ }^{1}$, Doctor of Technical Science, Professor,

T.B. Nikitina ${ }^{2}$, Doctor of Technical Science, Professor,

I.V. Bovdui ${ }^{1}$, PhD, Senior Research Scientist,

V.V. Kolomiets ${ }^{3}$, PhD, Associate Professor,

B.B. Kobylianskiy ${ }^{3}, P h D$, Associate Professor,

${ }^{1}$ State Institution «Institute of Technical Problems of Magnetism of the National Academy of Sciences of Ukraine»,

19, Industrialna Str., Kharkiv, 61106, Ukraine.

e-mail: kuznetsov.boris.i@gmail.com

${ }^{2}$ Kharkov National Automobile and Highway University, 25, Yaroslava Mudroho Str., Kharkov, 61002, Ukraine, e-mail: tatjana55555@gmail.com

${ }^{3}$ Educational scientific professional pedagogical Institute of Ukrainian Engineering Pedagogical Academy,

9a, Nosakov Str., Bakhmut, Donetsk Region, 84511, Ukraine, e-mail: nnppiuipa@ukr.net multi-story building by active shielding means. Electrical Engineering \& Electromechanics, 2021, no. 2, pp. 23-29. doi: 10.20998/2074-272X.2021.2.04. 